\title{
Neuroendocrine Mechanism of Onset of Puberty Sequential Reduction in Activity of Inhibitory and Facilitatory N-Methyl-D-Aspartate Receptors
}

\author{
Jean-Pierre Bourguignon, ${ }^{\star \star}$ Arlette Gérard, ${ }^{\star}$ Maria-Luz Alvarez Gonzalez, ${ }^{\ddagger}$ and Paul Franchimont ${ }^{\ddagger}$ \\ ${ }^{*}$ Department of Pediatrics and ${ }^{\ddagger}$ Radioimmunoassay Laboratory, University of Liège, B-4000 Liège, Belgium
}

\begin{abstract}
In humans and in several animal species, puberty results from changes in pulsatile gonadotropin-releasing hormone (GnRH) secretion in the hypothalamus. In particular, the frequency of pulsatile GnRH secretion increases at the onset of puberty, as can be shown by using hypothalamic explants of male rats of 15 and $25 \mathrm{~d}$. Previous observations from us and others suggested that the initiation of puberty could involve a facilitatory effect of excitatory amino acids mediated through $N$-methyl-D-aspartate (NMDA) receptors. We found that GnRH secretion could be activated through NMDA receptors only around the time of onset of puberty ( $25 \mathrm{~d}$ ). The aim of this study was to clarify why this activation did not occur earlier (at $15 \mathrm{~d}$ ) and could no longer be observed by the end of puberty (at $50 \mathrm{~d}$ ). We studied GnRH secretion in the presence of MK-801, a noncompetitive antagonist of NMDA receptors or AP-5, a competitive antagonist. We showed that, in the hypothalamus of immature male rats (15 d), a highly potent inhibitory control of pulsatile GnRH secretion in vitro was mediated through NMDA receptors. These data were confirmed in vivo because administration of the antagonist MK-801 $(0.001 \mathrm{mg} / \mathrm{kg})$ to immature male rats resulted in early pubertal development. Onset of puberty (25 d) was characterized by the disappearance of that NMDA receptor-mediated inhibition, thus unmasking a facilitatory effect also mediated through NMDA receptors. During puberty, there was a reduction in activity of this facilitatory control which was no longer opposed by its inhibitory counterpart. We conclude that a sequential reduction in activity of inhibitory and facilitatory NMDA receptors provides a developmental basis for the neuroendocrine mechanism of onset of puberty. (J. Clin. Invest. 1992. 90:1736-1744.) Key words: AP-5 • MK-801 • neuroexcitatory amino acids $\bullet$ puberty $\bullet$ pulsatile gonadotropinreleasing hormone secretion $\bullet N$-methyl-D-as jartate
\end{abstract}

\section{Introduction}

The precocious onset of sexual maturation can result from a premature activation of gonadotropin-releasing hormone

This work was presented in part at the annual meeting of the Endocrine Society, June 1991, Washington, DC.

Address reprint requests to Prof. J.-P. Bourguignon, Department of Pediatrics, University of Liège, CHR de la Citadelle, bd du 12e de Ligne 1, B4000 Liège, Belgium.

Received for publication 25 November 1991 and in revised form 21 April 1992

J. Clin. Invest.

(c) The American Society for Clinical Investigation, Inc.

$0021-9738 / 92 / 11 / 1736 / 09 \$ 2.00$

Volume 90, November 1992, 1736-1744
$(\mathrm{GnRH})^{1}$ neurons either induced chemically in laboratory animals $(1,2)$ or caused by pathological processes in humans (3). This indicates that the onset of puberty is determined by maturational changes in the hypothalamus or the suprahypothalamic central nervous system. In the hypothalamus, GnRH is secreted in a pulsatile manner driven by a pacemaker system or pulse generator (4-6). In different species, the onset of puberty is characterized by an increased frequency of pulsatile GnRH secretion (7-10). We have particularly studied the male rat which is prepubertal at $15 \mathrm{~d}$ of age. The most early pubertal changes in testicular size and spermatogenesis are seen at $25 \mathrm{~d}$, whereas the end of puberty is attained by $50 \mathrm{~d}$ of age (11). By using hypothalamic explants of male rats, we have shown that a twofold increase in frequency of GnRH secretory pulses occurred between 15 and $25 \mathrm{~d}$ of age (11). The mechanism controlling that increase in frequency of pulsatile GnRH secretion at the onset of puberty is not elucidated. This mechanism could consist of either switching off an inhibitory control such as that of opioid peptides $(12,13)$ and/or switching on a facilitatory control such as proposed for the excitatory amino acids, glutamate and aspartate $(1,2)$.

The excitatory role of these amino acids or their agonists, kainate and $N$-methyl-D-aspartate (NMDA), in controlling the pituitary-gonadal system has been extensively documented. These agonists have obvious excitatory effects in vivo $(1,2,14)$ and in vitro $(15,16)$ whereas an inhibition is obtained by using specific antagonists to NMDA receptors such as AP-5 or MK$801(17,18)$. Based on all these data, it was hypothesized that the NMDA receptors involved in GnRH secretion would be increasingly activated from the time of onset of puberty. We proposed to assess indirectly the activation of those receptors by using the noncompetitive antagonist MK-801 $(11,19)$ in that the antagonistic effect of this "use-dependent" compound was directly related to the degree of activation of the receptor by the agonist (20). Thus the sensitivity of GnRH secretion to the suppressing effect of MK-801 provided an index of endogenous activation of NMDA receptors involved in the GnRH pulse generator $(11,19)$. In this study we have tested the hypothesis that NMDA receptors could mediate not only a facilitatory control but also an inhibitory control of pulsatile $\mathrm{GnRH}$ secretion, particularly before onset of puberty.

\section{Methods}

Animals and products. Male Wistar rats (Janssen Pharmaceutica, Beerse, Belgium) housed in standardized conditions (14-h light/10-h

1. Abbreviations used in this paper: $\mathrm{CRH}$, corticotropin-releasing hormone; GnRH, gonadotropin-releasing hormone; $\mathrm{LH}$, luteinizing hormone; NMA, $N$-methyl-D,L-aspartate; NMDA, $N$-methyl-D-aspartate. 
darkness, $24-26^{\circ} \mathrm{C}$, free access to food and water, weaning at $21 \mathrm{~d}$ of age) were studied at different ages $(15,25,35$, and $50 \mathrm{~d})$. Culture medium for incubation of hypothalamic explants consisted of Eagle's minimum essential medium (MEM), purchased from Flow Laboratories, Inc., McLean, VA. The agonists of excitatory amino acids NMDA and $N$-methyl-D,L-aspartate (NMA), a racemic mixture, as well as veratridine, a depolarizing alcaloid opening the $\mathrm{Na}^{+}$channel (21), were purchased from Sigma Chemical Co., St. Louis, MO. (+)-5Methyl,10-11-dihydro-5H-dibenzo[a,d]-cyclohepten-5,10-imine maleate (MK-801), a noncompetitive NMDA receptor antagonist (22), was generously supplied by Merck, Sharp \& Dohme Research Laboratories, Rahway, NJ. DL-2-Amino-5-phosphonovaleric acid (AP-5), a competitive NMDA receptor antagonist (17), was purchased from Sigma Chemical Co. The highly specific RR-5 anti-GnRH antiserum was kindly provided by Dr. A. Root, St Petersburg, FL.

Incubation of hypothalamic explants and radioimmunoassay of $G n R H$. Retrochiasmatic hypothalamic explants were studied by using a procedure described in detail previously $(18,23)$. Briefly, 12 animals were studied in each experiment. After decapitation, the retrochiasmatic hypothalami were rapidly dissected and transferred to 12 individual chambers containing $0.5 \mathrm{ml}$ of Eagle's MEM enriched with glycine, magnesium, and glucose to obtain final concentrations of 10,1 , and 25 $\mathrm{mM}$, respectively. This was a static incubation system, the total incubation volume $(0.5 \mathrm{ml})$ being sampled and renewed every $7.5 \mathrm{~min}$ for 3-4 h. The collected fractions were kept frozen until assayed. GnRH was measured in the collected fractions following a radioimmunoassay procedure described previously $(23,24)$. The limit of detection was 5 $\mathrm{pg} / 7.5$-min fraction, which was the value assigned to data below that limit. The coefficient of variation was calculated by introducing $0.5 \mathrm{ml}$ of medium containing synthetic GnRH in the experimental system for $7.5 \mathrm{~min}$. This was done repeatedly on 15 occasions using different concentrations (10-50 pg/0.5-ml fraction) in the range of those secreted endogenously. The recovery was $94 \%$. Calculation of the coefficient of variation included variability resulting from the sampling procedure using different incubation chambers and the radioimmunoassay. The intraassay coefficient of variation varied between $8 \%$ and $14 \%$ for GnRH secretory levels of 50 and $10 \mathrm{pg} / 0.5-\mathrm{ml}$ fraction, respectively. Interassay coefficient of variation was $10-18 \%$. For GnRH pulse detection analysis, the $14 \%$ value was used in that data subjected to analysis were obtained within a single experiment and assay while some measured values were close to the detection limit of the assay.

Experimental protocols. Using 12 individual hypothalamic explants obtained at $15 \mathrm{~d}$ (six controls and six incubated individually in the presence of MK-801 during the whole study period of $240 \mathrm{~min}$ ), the effect of MK-801 on the frequency of spontaneous GnRH secretory pulses was studied. For each tested dose of MK-801 $\left(10^{-14}\right.$ to $\left.10^{-4} \mathrm{M}\right)$, six different explants were studied. A similar study was performed using $\mathrm{AP}-5\left(10^{-12}\right.$ to $\left.10^{-4} \mathrm{M}\right)$.

In another series of experiments using individual explants obtained at $15 \mathrm{~d}$ (six in each experiment), the increase in GnRH secretion induced by a $7.5-\mathrm{min}$ depolarization with veratridine $(50 \mu \mathrm{M})$ was studied repeatedly in the absence or in the presence of increasing MK-801 concentrations $\left(10^{-16}\right.$ to $\left.10^{-4} \mathrm{M}\right)$. The antagonist was used for $15 \mathrm{~min}$, including 7.5 min during veratridine stimulation. In an initial set of experiments, veratridine stimulatory episodes were performed at 52.5 min intervals, thus beyond the period of refractoriness caused by GnRH inhibitory autofeedback (25). In a second set of experiments, veratridine was used at 37.5 -min intervals, thus within the refractory period resulting in blunted GnRH response (25). The response of GnRH secretion to veratridine was calculated as the difference between the levels obtained immediately before and during the depolarization. In order to include data from different experiments in the same analysis, the data were expressed as a percentage of the initial response to veratridine.

In a final series of in vitro experiments, individual explants obtained at 15, 25, and $50 \mathrm{~d}$ of age were studied. Every $30 \mathrm{~min}$, the explants were exposed for $7.5 \mathrm{~min}$ to increasing concentrations of NMA (0.01-50 nM). For those experiments, NMA was used instead of
NMDA in that the former preparation was less expensive than the latter although, using a 10-fold factor between the different concentrations tested, we did not find any significant difference between GnRH secretory responses to NMA and NMDA. The effects of NMA on GnRH secretion was studied in the absence (controls) or in the presence of $10^{-14} \mathrm{M}$ of MK-801 throughout the whole experiment. The increment in GnRH secretion induced by NMA was calculated as the difference between GnRH secretory levels obtained immediately before and during exposure to NMA.

Immature male rats were treated using saline or MK-801 at three different doses $(0.1,0.01$, and $0.001 \mathrm{mg} / \mathrm{kg}$ body wt $)$ given as a daily s.c. injection from 9 to $16 \mathrm{~d}$ of age. The animals were distributed in three litters, each containing three controls and six animals receiving a similar dose of MK-801. The animals were killed at $35 \mathrm{~d}$ of age. The hypothalamic explants were used to study the inhibition of veratridineinduced secretion of GnRH by increasing concentrations of MK-801, as shown previously $(11,19)$. The data obtained were compared with those reported earlier in intact rats studied between 5 and $75 \mathrm{~d}$ of age. In addition, the testes were removed and weighed, and testicular cells were dissociated and studied by flow cytometry analysis as described earlier (11). This allowed calculating the proportion of elongated spermatids, the most mature form of germ cells identified using this technique.

Statistical analysis. The significance of GnRH secretory pulses observed spontaneously was assessed using the PULSAR program (26, $27)$ as described previously $(11,18)$. The significance of differences in interval between GnRH secretory pulses and differences in GnRH secretory responses to repeated veratridine challenges was calculated using ANOVA with correction for repeated determinations and the Scheffe $F$ test (28). To analyze the dose-response relationship between MK-801 concentration and GnRH response to veratridine, regression lines were calculated after logit transform of $\mathrm{GnRH}$ secretory response to veratridine and taking the logarithm of the dose. From these regression lines, the concentrations of MK-801 resulting in a 50\% inhibition of the release of $\mathrm{GnRH}\left(\mathrm{IC}_{50}\right)$ were calculated. The different regression lines and $\mathrm{IC}_{50}$ obtained after different treatment regimens in vivo were compared by covariance analysis (28). Comparison between GnRH secretory responses to NMA in control explants and in the presence of MK-801 was made using the $U$ test of Mann-Whitney. This test was also used to compare the proportion of elongated spermatids in testicular cell homogenates of intact rats and rats treated using MK-801. All results were considered to be significant at the $5 \%$ critical level.

\section{Results}

As shown in Fig. 1, the frequency of pulsatile GnRH secretion from 15-d-old explants was significantly increased in the presence of very low concentrations of the noncompetitive NMDA receptor antagonist, MK-801 $\left(10^{-13}\right.$ to $\left.10^{-11} \mathrm{M}\right)$. Incubation in the presence of $10^{-13} \mathrm{M}$ of MK-801 resulted in a mean 41-min interval between $\mathrm{GnRH}$ pulses, thus no longer different from that seen at $25 \mathrm{~d}(39 \pm 11$ min, mean $\pm 1 \mathrm{SD}, n=65$ explants). A further increase in MK-801 concentration $\left(10^{-10}\right.$ to $10^{-6} \mathrm{M}$ ) resulted in no significant differences in $\mathrm{GnRH}$ pulse frequency, although high MK-801 concentrations $\left(10^{-5}\right.$ and $10^{-4} \mathrm{M}$ ) reduced or suppressed pulsatile $\mathrm{GnRH}$ secretion. Using hypothalamic explants of 25-d-old rats (data not shown), we were unable to observe any increase in GnRH pulse frequency in the presence of low MK-801 concentrations $\left(10^{-13}\right.$ to $\left.10^{-11} \mathrm{M}\right)$ while we confirmed the inhibitory effect shown previously (11).

In Fig. 2 are shown the variations in frequency of pulsatile GnRH secretion from 15-d-old explants in the presence of AP5 , a competitive NMDA receptor antagonist. A low concentration of AP-5 $\left(10^{-10} \mathrm{M}\right)$ resulted in a slight but not significant increase in GnRH interpulse interval $(72 \pm 5$ vs. $65 \pm 6 \mathrm{~min})$ 

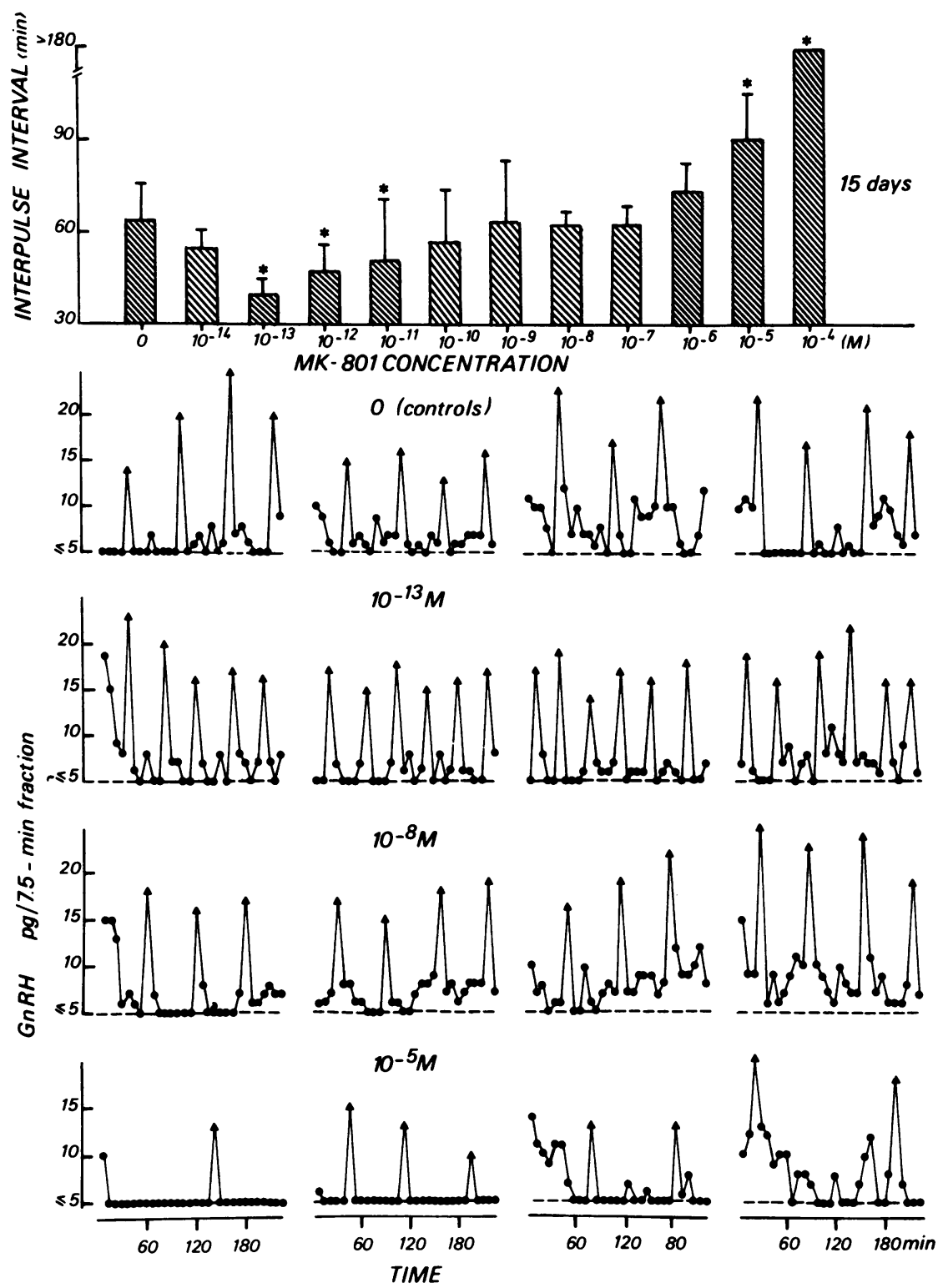

Figure 1. Effect of increasing concentrations of MK-801, a noncompetitive NMDA receptor antagonist, on the frequency of pulsatile GnRH secretion by hypothalamic explants of 15-d-old male rats. Upper panel: mean $( \pm 1 \mathrm{SD})$ interval between $\mathrm{GnRH}$ pulses from individual explants studied without or in the presence of MK-801 ( $n=6$ in each group). Lower panels: representative profiles of $\mathrm{GnRH}$ secretion from individual explants (four in each group) incubated in the absence of MK-801 (controls) or in the presence of $10^{-13}, 10^{-8}$, and $10^{-5} \mathrm{M}$ or MK-801. ( $\triangle$ ) Significant GnRH secretory pulse. *Significant difference in GnRH interpulse intervals versus controls. whereas a greater concentration of AP-5 $\left(10^{-4} \mathrm{M}\right)$ accounted for a significantly reduced interval $(41 \pm 6 \mathrm{~min})$. This latter effect was similar to that obtained using $10^{-13} \mathrm{M}$ of MK-801.

In Fig. 3 are shown representative profiles of GnRH secretion from 15-d-old hypothalamic explants exposed to veratridine repeatedly in the absence or in the presence of increasing MK-801 concentrations. When the interval between veratridine challenges was $52.5 \mathrm{~min}$, i.e., longer than the refractory period after a GnRH secretory episode (Fig. 3, upper panel), a similar GnRH response was obtained repeatedly in the absence of MK-801. The analysis of variance showed no significant difference in GnRH secretory response among the control explants although a significant change occurred when GnRH response to veratridine was studied in the presence of increasing concentrations of $\mathrm{MK}-801$. In using $10^{-12}$ to $10^{-6} \mathrm{M}$ of $\mathrm{MK}-$ 801 , no difference was seen whereas high MK-801 concentrations $\left(10^{-5}\right.$ to $\left.10^{-4} \mathrm{M}\right)$ resulted in a marked inhibition of GnRH secretion in response to veratridine.

When explants of 15-d-old rats were exposed to veratridine every $37.5 \mathrm{~min}$ (Fig. 3, lower panel), the initial secretory response of $\mathrm{GnRH}$ was followed by a reduction. This inhibitory effect was similarly observed at all subsequent depolarizing episodes. As shown previously, this effect resulted from the inhibitory autofeedback of GnRH operating because the interval between depolarizing episodes was within the refractory period of the pulse generator (25). In the presence of low MK-801 concentrations $\left(10^{-15}\right.$ to $\left.10^{-11} \mathrm{M}\right)$, the inhibition of GnRH response resulting from the autofeedback could be prevented since the response of $\mathrm{GnRH}$ to veratridine was restored and significantly greater than in control conditions. In using $10^{-15}$ to $10^{-11} \mathrm{M}$ of $\mathrm{MK}-801$, mean $\mathrm{GnRH}$ secretory response to veratridine was found to vary between $63 \%$ and $84 \%$ of initial response, whereas the response fell below $30 \%$ in the presence of higher MK-801 concentration as well as in control conditions. Using explants of $25-$ and 50 -d-old rats (data not shown), we found that the reduction of veratridine-induced secretion of GnRH by the inhibitory autofeedback could no longer be prevented by MK-801 $\left(10^{-15}\right.$ to $\left.10^{-6} \mathrm{M}\right)$. 

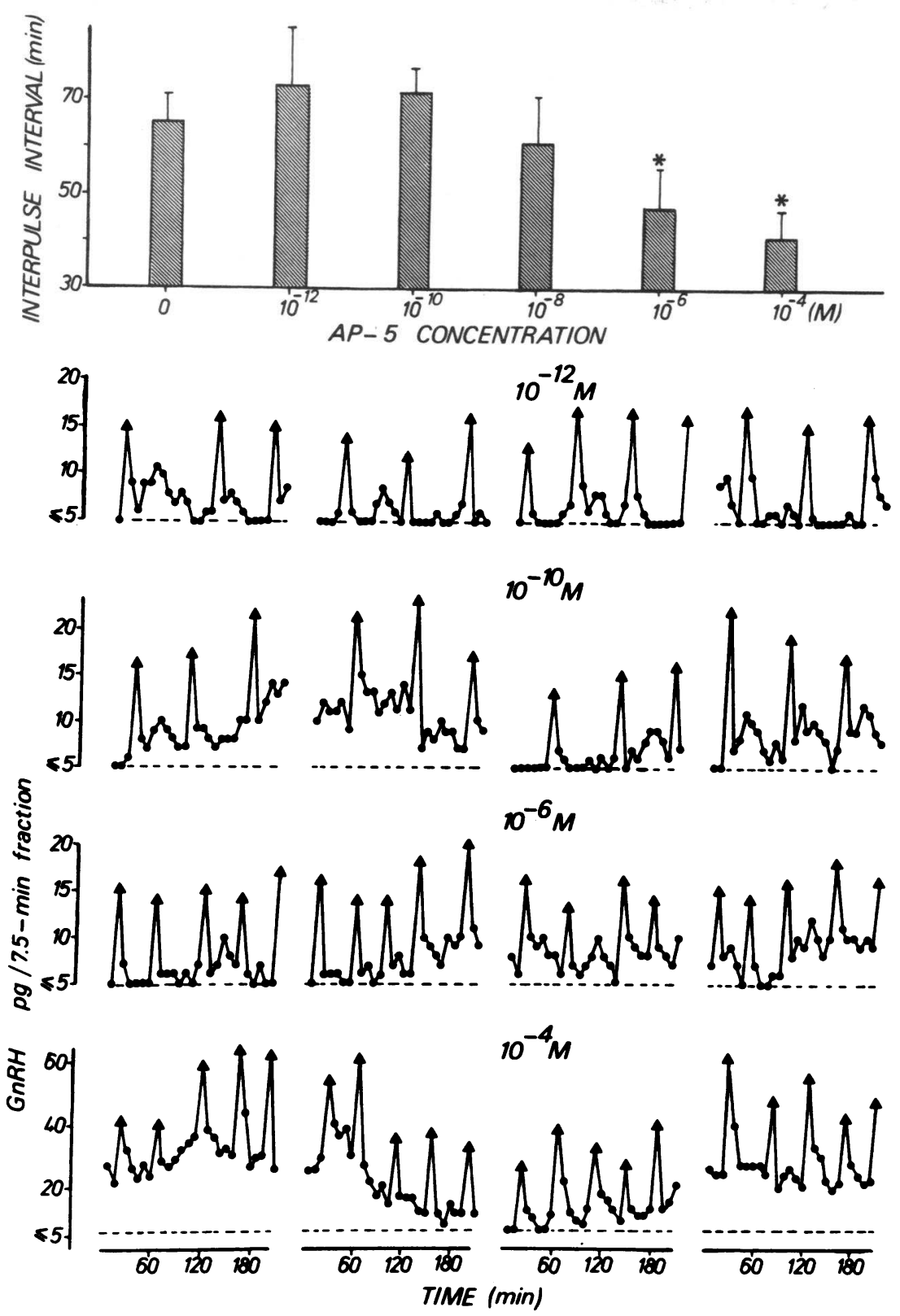

Figure 2. Effect of increasing concentrations of AP-5, a competitive NMDA receptor antagonist, on the frequency of pulsatile GnRH secretion by hypothalamic explants of 15 -d-old male rats. Upper panel: mean (+1 SD) interval between GnRH pulses from individual explants studied without or in the presence of AP-5 $(n=6$ in each group). Lower panels: representative profiles of GnRH secretion from individual explants (four in each group) incubated in the presence of $10^{-12}, 10^{-10}, 10^{-6}$, and $10^{-4} \mathrm{M}$ of AP-5. (A) Significant GnRH secretory pulse. *Significant difference in GnRH interpulse interval versus controls.
In Fig. 4 are shown the NMA-induced increments in GnRH secretion from hypothalamic explants of 15-, 25-, and 50 -d-old rats in control conditions or in the presence of a very low MK-801 concentration ( $10^{-14} \mathrm{M}$ ). In using hypothalamic explants of prepubertal rats ( $15 \mathrm{~d}$ ), MK-801 $10^{-14} \mathrm{M}$ resulted in a significantly increased $(P<0.05)$ secretion of GnRH in response to low concentrations of NMA $(0.05-1 \mathrm{mM})$. Such an effect was no longer observed using 5 or $10 \mathrm{mM}$ of NMA, which did not elicit any significant increase in GnRH secretion either in control conditions or in the presence of MK-801 $10^{-14}$ M. In both conditions, NMA 20 and $50 \mathrm{mM}$ caused a similar increase in GnRH secretion. At onset of puberty (25 d), there was a greater sensitivity of GnRH secretion to NMA than at 15 $\mathrm{d}$ in that $1 \mathrm{mM}$ of NMA resulted in a significant increase of GnRH secretion in control conditions. This effect was slightly potentiated in the presence of MK- $80110^{-14} \mathrm{M}$. By the end of sexual maturation ( $50 \mathrm{~d}$ ), GnRH secretion showed a low sensitivity to NMA in control conditions, similar to that seen at 15 d. However, this effect was no longer potentiated by MK-801 which resulted in a significant reduction of the response to 20 and $50 \mathrm{mM}$ of NMA.

In Fig. 5 are shown the long-term effects of antagonism of NMDA receptors in immature male rats by MK- 801 administration in vivo between 9 and $16 \mathrm{~d}$ of age. In the animals treated by using vehicle or MK-801 0.1 or $0.01 \mathrm{mg} / \mathrm{kg}$ per day, the developmental changes in $\mathrm{IC}_{50}$ of $\mathrm{MK}-801$ inhibiting $\mathrm{GnRH}$ response to veratridine in the hypothalamus and the pubertal increase in proportion of elongated spermatids in the testis were not affected because no significant differences were observed at $35 \mathrm{~d}$. In contrast, significantly earlier changes in those parameters $(P<0.05)$ were observed in rats treated by using the lowest dosage of MK-801 $(0.001 \mathrm{mg} / \mathrm{kg})$.

In Fig. 6, we propose a model integrating our observations on the developmental changes in the control of pulsatile GnRH secretion by neurons activating NMDA receptors. Our experimental preparation contains $\mathrm{GnRH}$ axons deafferented 


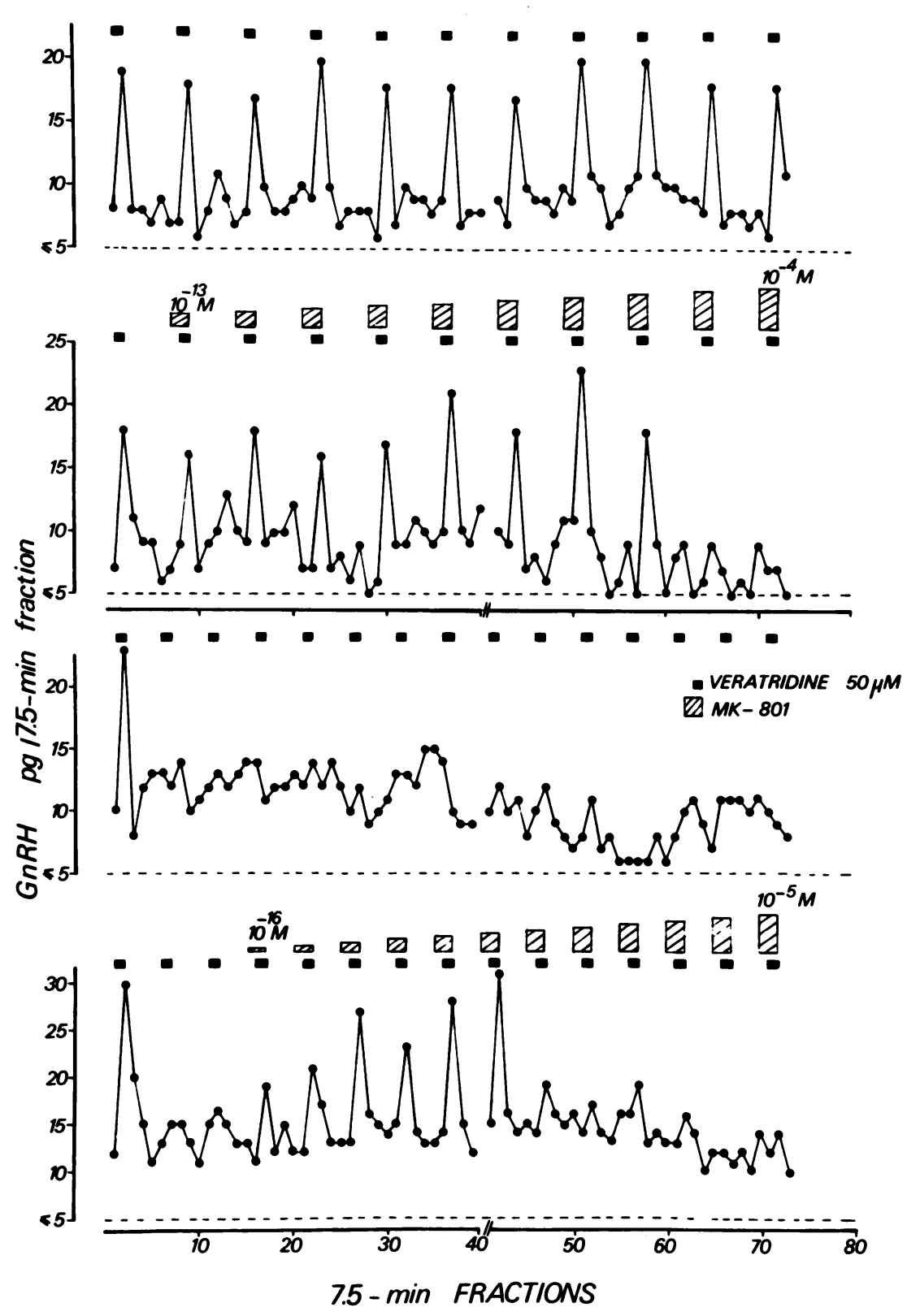

Figure 3. Representative profiles of GnRH secretion from individual hypothalamic explants of 15-d-old rats exposed repeatedly to veratridine $(50 \mu \mathrm{M})$ for $7.5 \mathrm{~min}$, this depolarizing episode occurring either in the absence of MK-801 or in the presence of increasing concentrations of MK-801. The secretory response of $\mathrm{GnRH}$ to veratridine is studied at 52.5 - $\mathrm{min}$ intervals ( upper panels) or at 37.5-min intervals (lower panels). from their perikarya and modulated presynaptically by a pacemaker system or pulse generator where neurons activating excitatory and inhibitory NMDA receptors can affect the occurrence of GnRH secretory pulses. This effect can be exerted either through variations in the frequency of the pulse generator or through variations in the amplitude of the stimulation so that some stimulation of reduced intensity would not result in any detectable secretory pulse. In the prepubertal male rat, at $15 \mathrm{~d}$, a potent NMDA receptor-mediated inhibitory control of the GnRH pulse generator restrains the frequency of pulses and prevents the expression of an active excitatory control mediated through a similar type of receptors. At $25 \mathrm{~d}$, the inhibitory pathway has lost much of its potency so that the activity of the excitatory control can be fully expressed. This results in an increased frequency of pulsatile GnRH secretion. Between 25 and $50 \mathrm{~d}$, i.e., during puberty, the activity of the excitatory pathway decreases as well in that it is no longer opposed by a potent inhibitory pathway. Therefore, a low activity of the excit- atory pathway can be sufficient to keep the pulse generator working in a pubertal manner.

\section{Discussion}

In this study, we directly evaluated the developmental changes in the control of pulsatile GnRH secretion by activation of NMDA receptors. Such a study was only possible after we had validated the suitability of our experimental model and made the following observations: ( $a$ ) Despite the absence of GnRH perikarya in the studied hypothalamic explants which do not include the preoptic area (29), pulsatile GnRH secretion could be observed in vitro $(18,23,24)$. This indicated that secretory activity of GnRH axons could be modulated by a neuronal pulse-generating machinery included in the studied explants. (b) Pulsatile secretion of GnRH by these explants showed a twofold increase in frequency by the time of onset of puberty $(11,24)$. (c) The control of the interval between GnRH secre- 


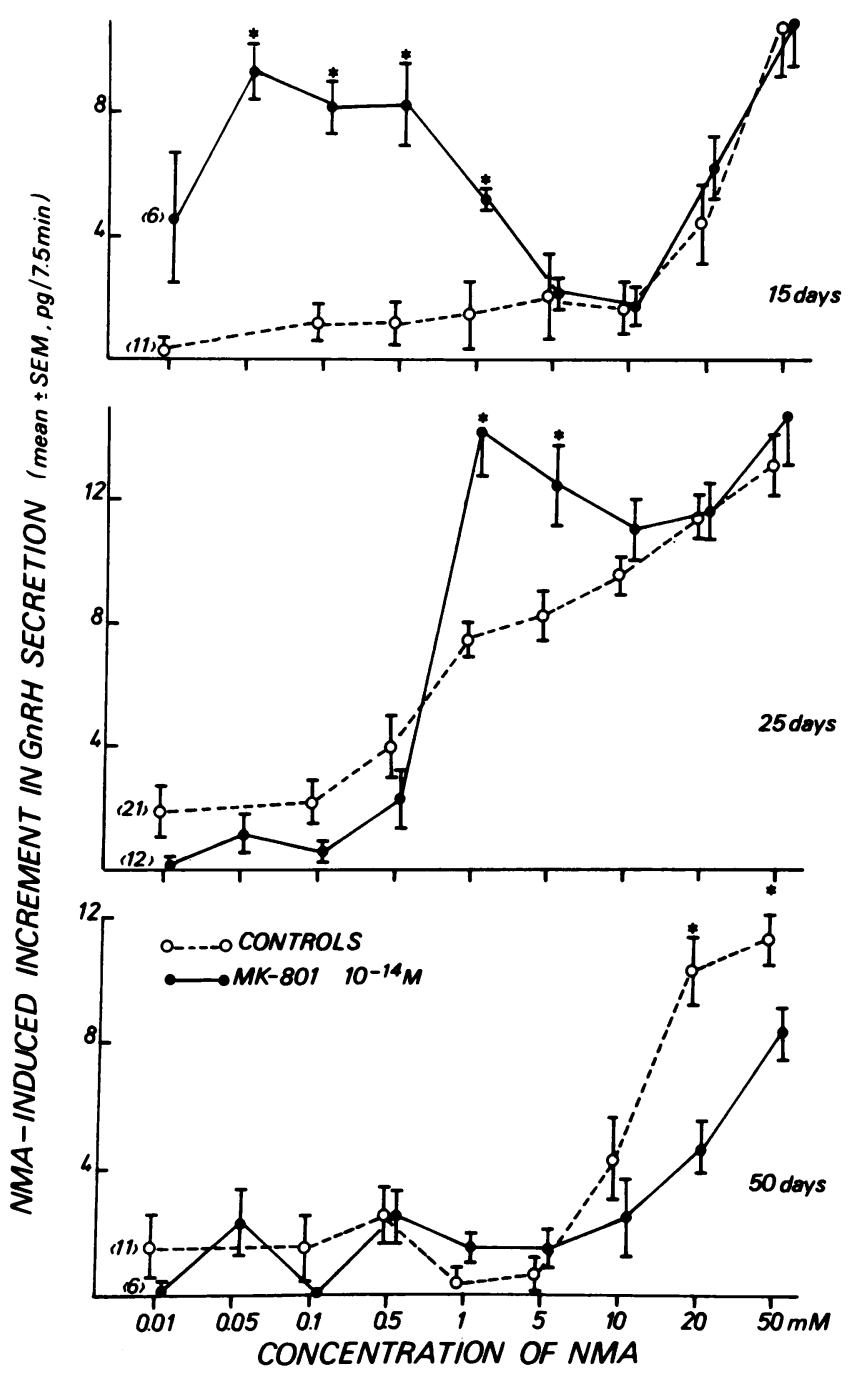

Figure 4. Increment in GnRH secretion from hypothalamic explants obtained at 15,25 , and $50 \mathrm{~d}$ and repeatedly exposed for $7.5 \mathrm{~min}$ to NMA at increasing concentrations. The study is performed in the absence (O) or in the presence $(\bullet)$ of $10^{-14} \mathrm{M}$ of MK-801. The number of individual explants studied in each group is indicated between parentheses. *Significant difference between control and MK-801 groups.

tory pulses involved an ultrashort inhibitory autofeedback. On account of this process, a GnRH secretory pulse was followed by a period of refractoriness which was longer before puberty than from the time of onset of puberty (25). (d) This ultrashort feedback of GnRH could be observed after a pulse of $\mathrm{GnRH}$ secretion induced by veratridine, a depolarizing agent used as a probe of GnRH secretory pulse $(19,25)$.

The occurrence of episodic increase in GnRH secretion using a static incubation system is unlikely to reflect a methodological artefact because these episodic changes are modulated by changes in culture conditions such as calcium, glucose, magnesium and glycine concentrations $(15,23)$. In addition, the changes in episodic GnRH secretion that we have reported, such as increase in frequency at onset of puberty, are consistent with data obtained in vivo (7-10). Finally, because this research was a continuation of previous studies, it was important to work in similar conditions for the present investigation. Nonetheless, a possible influence of the sampling technique on the occurrence of $\mathrm{GnRH}$ pulses using the static incubation system cannot be ruled out. Studies using a continuous perifusion system are in progress.

The investigation of the role of NMDA receptors in the control of onset of puberty was based on the following observations: ( $a$ ) The hypothalamic explants contained NMDA receptors involved in the physiological control of GnRH secretion inasmuch as the agonist NMA could elicit GnRH secretion (15) and the antagonist MK-801 could suppress pulsatile GnRH secretion (18). (b) The degree of endogenous activation of NMDA receptors involved in GnRH secretion could be estimated indirectly using the noncompetitive antagonist MK801 because its antagonistic effect was use or agonist dependent (20). Therefore, the sensitivity to the antagonistic effect of MK-801 was directly related to the level of activation of the NMDA receptors by their agonist. We showed previously that such a concept applied to GnRH secretion and that the sensitivity to MK-801 effects could be regarded as an index of endogenous activation of the studied receptors $(11,19)$. (c) Both the sensitivity of GnRH secretion to the suppressing effect of MK801 and the response to the administration of NMA increased markedly by the time of onset of puberty (11). This indicated that excitatory amino acids playing a facilitatory role in $\mathrm{GnRH}$ secretion were increasingly activated at that time. Such an hypothesis was consistent with numerous studies showing the stimulatory effect of excitatory amino acids on GnRH and/or luteinizing hormone $(\mathrm{LH})$ secretion in the male rat $(14,30$ $32)$, the female rat $(2,16,17,32-36)$, the hamster $(37,38)$, the lamb (39), and the monkey $(1,40)$.

Based on those observations, the neuroendocrine changes leading to onset of puberty could be viewed as the development or the activation of a facilitatory pathway controlling $\mathrm{GnRH}$ secretion through NMDA receptors. Such a concept did not necessarily require any restraining component in that the quiescent phase of the pituitary-gonadal axis before onset of puberty could result from an absent or low activity of the facilitatory pathway. However, this interpretation could not account for a puzzling observation from our group (11) and Cicero et al. (41): the increased activation of NMDA receptors seen at onset of puberty was transient because the level of activation of those receptors was reduced by the end of puberty and similar to that seen before onset of puberty. We hypothesized that the increased secretion of gonadal hormones during puberty could account for such changes. However, we showed recently that the developmental changes in activation of NMDA receptors involved in GnRH secretion occurred in orchidectomized rats as in intact animals, indicating that this maturational neuroendocrine process was independent of the gonads (19).

The hypothesis that NMDA receptors could mediate a not only facilitatory but also inhibitory control of GnRH secretion emerged from the incidental observation that the long refractory period separating two veratridine stimulatory episodes at $15 \mathrm{~d}$ of age was no longer operative in the presence of the NMDA receptor antagonist MK-801 (42). The present data provide direct evidence of an inhibitory control of pulsatile GnRH secretion in intact immature animals, in vitro and in vivo. The use of two different NMDA receptor antagonists such as MK-801 and AP-5 resulted in findings consistent with their different mechanisms of action. As a noncompetitive and use-dependent antagonist, MK-801 was effective in accelerating GnRH pulse frequency at remarkably low concentrations, suggesting that inhibitory NMDA receptors were very potently 

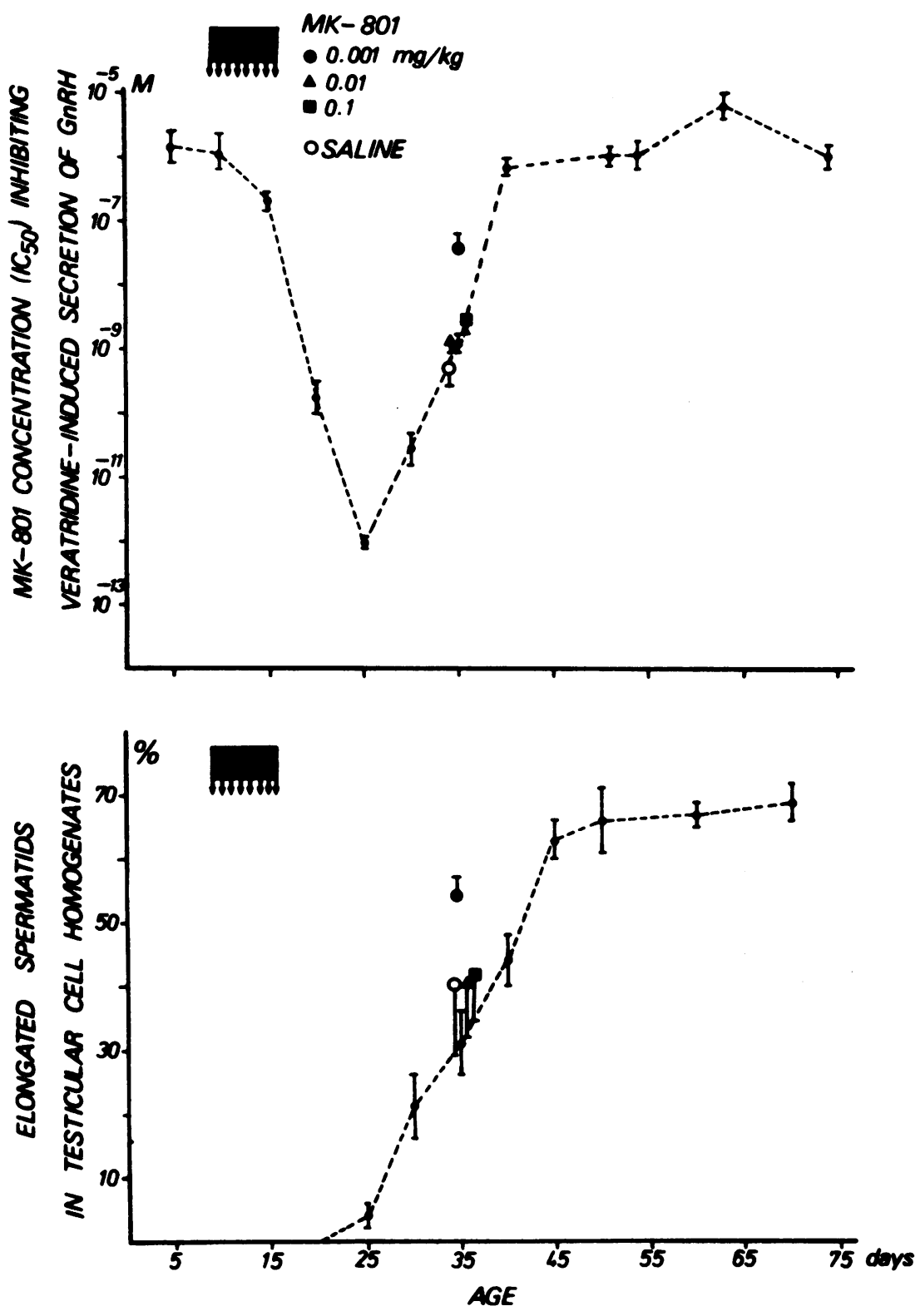

Figure 5. Upper panel: mean concentration $( \pm \mathrm{SD})$ of MK-801 required for a $50 \%$ inhibition $\left(I_{C_{50}}\right)$ of veratridine-induced secretion of GnRH by hypothalamic explants of male rats killed at $35 \mathrm{~d}$ of age after daily s.c. administration of MK-801 at three different dosages or saline between 9 and $16 \mathrm{~d}$ of age. Lower panel: proportion of elongated spermatids (percentage relative to total testicular cells) identified by flow cytometry analysis of testicular cell homogenates in the same animals as above. The dotted lines represent data (mean \pm SD) obtained in intact rats at different ages between 5 and $74 \mathrm{~d}$.

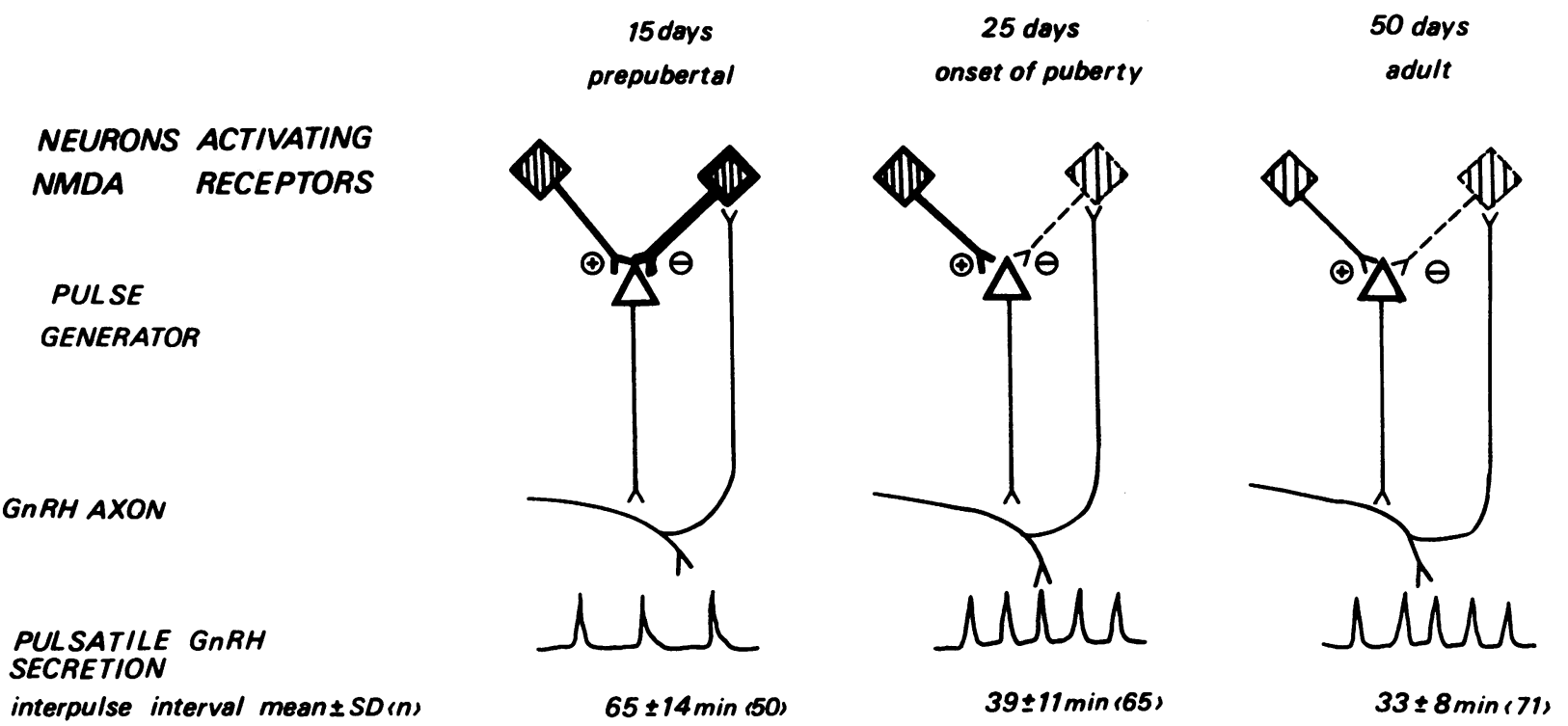

Figure 6. Schematic representation of the developmental changes in activation of inhibitory and facilitatory NMDA receptors modulating the GnRH pulse generator in the retrochiasmatic part of the rat hypothalamus and thereby determining an increase in the frequency of pulsatile secretion of GnRH. 
activated in the hypothalamus of immature male rats. By using AP-5, a similar acceleration of GnRH pulse frequency could be obtained though high concentrations were required as expected from the competitive nature of this antagonist. Further confirmation of the existence of NMDA receptor inhibition before puberty was obtained through the early development of puberty after administration of MK-801 to immature animals. This could be regarded as a long-term effect since the animals were treated between days 9 and 16 whereas the neuroendocrine and testicular effects were studied at $35 \mathrm{~d}$ of age. Thus, the consequences of an experimental neuroendocrine manipulation restricted to $1 \mathrm{wk}$ in immature animals were still observable 3 wks later, during puberty.

Although we disclosed a potent inhibitory role of NMDA receptors in restraining pulsatile GnRH secretion in the hypothalamus of immature rats, we showed that a facilitatory pathway was already established at that age. This was shown by the suppression of pulsatile or veratridine-induced GnRH secretion in the presence of high MK-801 concentrations at $15 \mathrm{~d}$ and by the highly sensitive response of GnRH to NMA in explants with inhibitory NMDA receptors blocked using extremely low MK-801 concentrations. In using AP-5, this dual role of NMDA was not apparent because very high concentrations were required to antagonize the inhibitory receptors. In contrast, the dual role of NMDA receptors in the immature hypothalamus was obvious using MK-801 to study pulsatile GnRH secretion as well as GnRH secretory response to veratridine and NMDA. It is possible that we overestimated the level of endogenous activation of NMDA receptors involved in a facilitatory effect at $15 \mathrm{~d}$ in that blockade of the inhibitory component could result in a compensatory activation of the facilitatory receptors. However, this hypothesis does not invalidate the concept of a dual system with prominently inhibitory effects at $15 \mathrm{~d}$. Because the NMDA receptors are mainly inhibitory and, to a lesser extent, facilitatory to GnRH secretion in the immature rat, it is understandable that only low doses of MK-801 resulted in early puberty. Based on use dependency, those low doses $(0.001 \mathrm{mg} / \mathrm{kg}$ per day $)$ blocked preferentially the highly activated inhibitory receptors whereas higher doses $(0.01$ and $0.1 \mathrm{mg} / \mathrm{kg}$ per day) interacting with both inhibitory and facilitatory receptors resulted in no effect on timing of puberty. The dual role of NMDA receptors in the control of GnRH secretion may help in understanding some previous findings not consistent with a solely facilitatory role of NMDA receptors. For instance, precocious vaginal opening was induced by neonatal administration of monosodium glutamate (35) known to usually inhibit the pituitary-gonadal axis (4345 ). Also, sexual maturation was delayed but not completely suppressed by prolonged in vivo administration of NMDA receptor antagonists $(33,35)$.

The changes in frequency of pulsatile $\mathrm{GnRH}$ secretion that we have observed could result either from true differences in frequency of activity of the GnRH pulse generator or from differences in amplitude of GnRH secretory pulse, thus being detectable or below the threshold for detection of a significant pulse. The relief by MK-801 of the refractory period following a veratridine-induced pulse of $\mathrm{GnRH}$ secretion strongly suggests that a frequency-modulated mechanism accounts for the inhibitory effects mediated through NMDA receptors. It is possible that antagonism of NMDA receptors would result in reduced neurosecretion of corticotropin releasing hormone (CRH) which can be involved in the inhibitory regulation of GnRH secretion. Such an hypothesis was raised by Reyes et al.
(46) based on the inhibitory action of NMA on pulsatile LH secretion in ovariectomized monkeys while cortisol was stimulated by the agonist. However, sex steroid replacement therapy resulted in an increase of $\mathrm{LH}$ and cortisol in response to NMA, the NMA-induced inhibition of LH being no longer observed whereas cortisol response was unchanged (47). This suggested that control of GnRH and CRH secretion through NMDA receptors could be dissociated, increased $\mathrm{CRH}$ secretion being not necessarily associated with reduced GnRH secretion.

Based on the dual system that we observed, it is conceivable that puberty results from sequential changes in the balance between inhibitory and facilitatory effects mediated through NMDA receptors. Both effects could show a reduction in activity with age. First, the inhibitory receptors would be less active at onset of puberty, resulting in the disclosure of the activity of the facilitatory receptors. These receptors being no longer opposed by their potent inhibitory counterpart would in turn be less active after onset of puberty, thus accounting for the reduction in response to NMDA and the loss of sensitivity to MK801 seen throughout puberty. According to this hypothesis, a common developmental feature of the inhibitory and facilitatory effects is a reduction in activity with age. Such a concept is in agreement with the observation that maturation of the receptors to excitatory amino acids in different areas of the central nervous system is characterized by a peak activity during the first week of postnatal life and a subsequent decline to a minimal activity attained by 3-5 wk of life (48-50). Very recently, dramatic changes in current generated through NMDA receptor activation were shown between 15 and $25 \mathrm{~d}$ (51). In addition, the toxic effects of monosodium glutamate or NMDA on hypothalamic neurons are selectively more potent during the early postnatal life than later $(45-47,52)$. Thus, the hypothalamic process of neuroendocrine maturation leading to onset of puberty can be related to the more general process of central nervous system maturation characterized by the progressive reduction in activity of some receptors to excitatory amino acids. Then, the interplay between inhibitory and facilitatory pathways activating such receptors could be a key mechanism to account for a timed event such as onset of puberty.

\section{Acknowledgments}

We thank Dr. A. Root for the generous gift of anti-GnRH serum and Merck, Sharp \& Dohme Research Laboratories for the kind supply of MK-801. We acknowledge the excellent secretarial assistance of Mrs. J. Laurent and M. Beyer.

This study was supported by grant 3.4574 .87 from the Fonds de la Recherche Scientifique Médicale (Belgium), a grant from the Faculty of Medicine, University of Liège, and a grant from Kabi-Pharmacia, Stockholm, Sweden.

\section{References}

1. Plant, T. M., V. L. Gay, G. R. Marshall, and M. Arslan. 1989. Puberty in monkeys is triggered by chemical stimulation. Proc. Natl. Acad. Sci. USA. 86:2506-2510.

2. Urbanski, H. K., and S. R. Ojeda. 1987. Activation of luteinizing hormonereleasing hormone release advances the onset of female puberty. Neuroendocrinology. 46:273-276.

3. Kaplan, S. L., and M. M. Grumbach. 1990. Pathophysiology and treatment of sexual precocity. J. Clin. Endocrinol. Metab. 71:785-789.

4. Belchetz, P. E., T. M. Plant, Y. Nakai, E. J. Keogh, and E. Knobil. 1978. Hypophysial responses to continuous and intermittent delivery of hypothalamic gonadotropin-releasing hormone. Science (Wash. DC). 202:631-633. 
5. Wildt, L., G. Marshall, and E. Knobil. 1980. Experimental induction of puberty in the infantile female rhesus monkey. Science (Wash. DC). 207:13731375.

6. Knobil, E. 1989. The GnRH pulse generator. In The Control of the Onset of Puberty III. H. A. Delemarre-Van de Waal, T. M. Plant, G. P. Van Rees, and J. Schoemaker, editors. Excepta Medica, Amsterdam. 11-20.

7. Ryan, K. D., and S. L. Robinson. 1985. A rise in tonic luteinizing hormone secretion occurs during photoperiod-stimulated sexual maturation of the female ferret. Endocrinology. 116:2013-2018.

8. Huffman, L. J., E. K. Inskeep, and R. L. Goodman. 1987. Changes in episodic luteinizing hormone secretion leading to puberty in the lamb. Biol. $R e$ prod. 37:755-761.

9. Rodriguez, R. E., and M. E. Wise. 1989. Ontogeny of pulsatile secretion of gonadotropin-releasing hormone in the bull calf during infantile and pubertal development. Endocrinology. 124:248-256.

10. Claypool, L. E., G. Watanabe, and E. Terasawa. 1990. Effects of electrical stimulation of the medial basal hypothalamus on the in vivo release of luteinizing hormone-releasing hormone in the prepubertal and peripubertal female monkey. Endocrinology. 127:3014-3022.

11. Bourguignon, J. P., A. Gerard, J. Mathieu, A. Mathieu, and P. Franchimont. 1990. Maturation of the hypothalamic control of pulsatile gonadotropin releasing hormone at onset of puberty. I. Increased activation of $N$-methyl-Daspartate receptors. Endocrinology. 127:873-881.

12. Blank, M. S., A. E. Panerai, and H. G. Friesen. 1979. Opioid peptides modulate LH secretion during sexual maturation. Science (Wash. DC). 203:1129-1131.

13. Bhanot, R., and M. Wilkinson. 1983. Opiatergic control of gonadotropin secretion during puberty in the rat: a neurochemical basis for the hypothalamic "Gonadostat"? Endocrinology. 113:596-603.

14. Ondo, J. G., D. D. Wheeler, and R. M. Dom. 1988. Hypothalamic site of action for $N$-methyl-D-aspartate (NMDA) on LH secretion. Life Sci. 43:22832286.

15. Bourguignon, J. P., A. Gerard, and P. Franchimont. 1989. Direct activation of GnRH secretion through different receptors to neuroexcitatory amino acids. Neuroendocrinology. 49:402-408.

16. Donoso, A. O., F. J. Lopez, and A. Negro-Vilar. 1990. Glutamate receptors of the non- $N$-methyl-D-aspartatic acid type mediate the increase in luteinizing hormone releasing hormone release by excitatory amino acids in vitro. Endocrinology. 126:414-420.

17. Arslan, M., C. R. Pohl, and T. M. Plant. 1988. DL-2-Amino-5-phosphono pentanoic acid, a specific $N$-methyl-D-aspartic acid receptor antagonist, sup presses pulsatile LH release in the rat. Neuroendocrinology. 47:465-468.

18. Bourguignon, J. P., A. Gerard, J. Mathieu, J. Simons, and P. Franchimont. 1989. Pulsatile release of gonadotropin releasing hormone from hypothalamic explants is restrained by blockade of $N$-methyl-D,L aspartate receptors. Endocrinology. 125:1090-1096.

19. Bourguignon, J. P., A. Gerard, M. L. Alvarez-Gonzalez, L. Fawe, and P. Franchimont. 1992. Gonadal independent developmental changes in activation of $N$-methyl-D aspartate receptors involved in gonadotropin-releasing hormone secretion. Neuroendocrinology. 55:634-641.

20. Foster, A. C., and E. H. F. Wong. 1987. The novel anticonvulsivant MK-801 binds to the activated state of the $N$-methyl-D-aspartate receptor in rat brain. Br. J. Pharmacol. 91:403-409.

21. Ohta, M., T. Narohashi, and R. F. Keeler. 1973. Effects of veratrum alkaloids on membrane potential and conductance of squid and crayfish giant axons. J. Pharmacol. Exp. Ther. 184:143-154.

22. Wong, E. F., J. A. Kemp, T. Priestley, A. R. Knight, G. N. Woodruff, and L. L. Iversen. 1986. The anticonvulsant MK-801 is a potent $N$-methyl-D-aspartate antagonist. Proc. Natl. Acad. Sci. USA. 83:7104-7108.

23. Bourguignon, J. P., A. Gerard, G. Debougnoux, J. Rose, and P. Franchimont. 1987. Pulsatile release of gonadotropin-releasing hormone (GnRH) from the rat hypothalamus in vitro: calcium and glucose dependency and inhibition by superactive GnRH analogs. Endocrinology. 121:993-999.

24. Bourguignon, J. P., and P. Franchimont. 1984. Puberty-related increase in episodic LHRH release from rat hypothalamus in vitro. Endocrinology. 114:1941-1943.

25. Bourguignon, J. P., A. Gerard, and P. Franchimont. 1990. Maturation of the hypothalamic control of pulsatile gonadotropin-releasing hormone at onset of puberty. II. Reduced potency of an inhibitory autofeedback. Endocrinology. 127:2884-2890.

26. Gitzen, J. F., and V. D. Ramirez. 1987. PC Pulsar-Pulsar pulse analysis for the IBM-PC. Psychoneuroendocrinology. 12:3-6.

27. Merriam, G. R., and K. W. Wachter. 1982. Algorithms for the study of episodic hormone secretion. Am. J. Physiol. 243:E310-E318.

28. Armitage, P. A., and D. Berry. 1987. Statistical Methods in Medical Research. Blackwell, Oxford.

29. Barry, J., G. E. Hoffman, and S. Wray. 1985. LHRH-containing systems.
In GABA and Neuropeptides in the CNS, Part I. Handbook of Chemical Neuroanatomy. Volume 4. A. Björklund and T. Hökfelt, editors. Elsevier, Amsterdam. $166-215$.

30. Farah, J. M., S. R. Tadimeti, S. J. Mick, K. E. Coyne, and S. Iyengar. 1991. $N$-Methyl-D-aspartate treatment increases circulating adrenocorticotropin and luteinizing hormone in the rat. Endocrinology. 128:1875-1880.

31. Petersen, S. L., S. McCrone, M. Keller, and E. Gardner. 1991. Rapid increase in LHRH mRNA levels following NMDA. Endocrinology. 129:16791681.

32. Saitoh, Y., A. J. Silverman, and M. J. Gibson. 1991. Effects of $N$-methylD,L-aspartic acid on luteinizing hormone secretion in normal mice and in hypogonadal mice with fetal preoptic area implants. Endocrinology. 128:2432-2440.

33. Urbanski, H. F., S. R. Ojeda. 1990 . A role for $N$-methyl-D-aspartate receptors in the control of LH secretion and initiation of female puberty. Endocrinology. 126:1774-1776.

34. Lopez, F. J., A. O. Donoso, and A. Negro-Vilar. 1990. Endogenous excitatory amino acid neurotransmission regulates the estradiol-induced LH surge in ovariectomized rats. Endocrinology. 126:1771-1773.

35. MacDonald, M., and M. Wilkinson. 1990. Peripubertal treatment with $\mathrm{N}$-methyl-D-aspartic acid or neonatally with monosodium glutamate accelerates sexual maturation in female rats, an effect reversed by MK-801. Neuroendocrinology. 52:143-149.

36. Brann, D. W., and V. B. Mahesh. 1991. Endogenous excitatory amino acid involvement in the preovulatory and steroid-induced surge of gonadotropins in the female rat. Endocrinology. 128:1541-1547.

37. Urbanski, H. F. 1990. A role for $N$-methyl-D-aspartate receptors in the control of seasonal breeding. Endocrinology. 127:2223-2228.

38. Meredith, J. M., F. W. Turek, J. E. Levine. Pulsatile luteinizing hormone responses to intermittent $N$-methyl-D,L-aspartate administration in Hamsters exposed to long- and short-day photoperiods. Endocrinology. 129:1714-1720.

39. Ebling, F. J. P., R. I. Wood, F. J. Karsch, L. A. Vannerson, J. M. Suttie, D. C. Bucholtz, R. E. Schall, and D. L. Foster. 1990. Metabolic interfaces between growth and reproduction. III. Central mechanisms controlling pulsatile luteinizing hormone secretion in the nutritionally growth-limited female lamb. Endocrinology. 126:2719-2727.

40. Wilson, R. C., and E. Knobil. 1982. Acute effects of $N$-methyl-D,Laspartate on the release of pituitary gonadotropins and prolactin in the adult female rhesus monkey. Brain Res. 248:177-179.

41. Cicero, T. J., E. R. Meyer, and R. D. Bell. 1988. Characterization and possible opioid modulation of $N$-methyl-D-aspartic acid induced increases in serum luteinizing hormone levels in the developing male rat. Life Sci. 42:17251732.

42. Bourguignon, J. P., A. Gerard, L. Fawe, M. L. Alvarez-Gonzalez, and P. Franchimont. 1991. Neuroendocrine control of the onset of puberty: secretion of gonadotropin-releasing hormone from rat hypothalamic explants. Acta Paediatr. Scand. Suppl. 372:19-25.

43. Olney, J. W. 1969. Brain lesions, obesity and other disturbances in mice treated with monosodium glutamate. Science (Wash. DC). 164:719-721.

44. Burde, R. M., B. Schainker, and J. Kayes. 1971. Acute effect of oral and subcutaneous administration of monosodium glutamate on the hypothalamus in mice and rats. Nature (Lond.). 233:58-60.

45. Dada, M. O., and C. A. Blake. 1984. Administration of monosodium glutamate to a neonatal male rats: alterations in the gonadotrophs and in gonadotrophin secretion. Neuroendocrinology. 38:490-497.

46. Reyes, A., J. Luckhaus, and M. Ferin. 1990. Unexpected inhibitory action of $\mathrm{N}$-methyl-D,L-aspartate on luteinizing hormone release in adult ovariectomized rhesus monkeys: a role of the hypothalamic-adrenal axis. Endocrinology. 127:724-729.

47. Reyes, A., L. Xia, and M. Ferin. 1991. Modulation of the effects of $\mathrm{N}$ methyl-D,L-aspartate on luteinizing hormone by the ovarian steroids in the adult rhesus monkey. Neuroendocrinology. 54:405-411.

48. Nicoletti, F., M. J. Iadarola, J. T. Wuroblewski, and E. Costa. 1986. Excitatory amino acid recognition sites coupled with inositol phospholipid metabolism: developmental changes and interaction with 1-adrenoreceptors. Proc. Natl. Acad. Sci. USA. 83:1931-1935.

49. Tremblay, E., M. P. Roisin, A. Represa, C. Charriaut-Marlangue, and Y. Ben-Ari. 1988. Transient increased density of NMDA binding sites in the developing rat hippocampus. Brain Res. 461:393-396.

50. Dudek, S. M., W. D. Bowe, and M. F. Bear. 1989. Postnatal changes in glutamate stimulated phosphoinositide turnover in rat neocortical synaptoneurosomes. Dev. Brain Res. 47:123-128.

51. Hestrin, S. 1992. Developmental repulsion of NMDA receptor-mediated synaptic currents at a central synapse. Nature (Lond.). 357:686-689.

52. McDonald, J. W., F. S. Silverstein, and M. V. Johnston. 1988. Neurotoxicity of $N$-methyl-D-aspartate is markedly enhanced in developing rat central nervous system. Brain Res. 459:200-203. 